\title{
DIAGNÓSTICO DE BOAS PRÁTICAS POR MEIO DE USO DE APLICATIVO MÓVEL: ESTUDO DE CASO EM GALETERIAS NO SUL DO BRASIL
}

\author{
DIAGNOSIS OF GOOD PRACTICES BY MEANS OF USING MOBILE \\ APPLICATION: CASE STUDY IN GALETERIAS IN THE SOUTH OF BRAZIL
}

\author{
Virgílio José Strasburg1', Karen Cristina Rigo² e Janaína Guimarães Venzke ${ }^{3}$
}

\section{RESUMO}

Restaurantes para coletividades devem ter como um de seus objetivos garantir refeições adequadas sob os critérios higienicossanitários. O uso de listas de verificação são recursos para auxiliar a adequação de boas práticas em serviços de alimentação. O objetivo deste trabalho foi avaliar o nível de adequação às boas práticas por meio da utilização de aplicativo móvel, em uma rede de galeterias no sul do Brasil. Trata-se de um estudo descritivo, quantitativo e com uso de dados secundários. Foram analisados os resultados obtidos de inspeções, aplicadas por meio de instrumento utilizado em aplicativo móvel de celular adaptado, da legislação sanitária brasileira. No período investigado, de abril de 2017 a janeiro de 2018, foram avaliadas as 143 inspeções realizadas nos 10 restaurantes da rede. Não foram encontradas relações entre a quantidade de inspeções com os percentuais de adequação higienicossanitárias. O restaurante que teve o menor número de inspeções apresentou o maior percentual de não conformidades. O restaurante com o melhor percentual atingiu $67 \%$ de adequação. Um estabelecimento atingiu $76 \%$ de não conformidade. Destaca-se a importância de se fazer uso da tecnologia para dar suporte na atuação do nutricionista. Utilizar recursos de aplicativos móveis, como os disponíveis para aparelhos celulares, pode ser relevante para fazer a avaliação dos resultados em tempo real em restaurantes.

Palavras chave: Alimentação Coletiva, Boas Práticas de Manipulação, Checklist, Restaurantes, Segurança de Alimentos, Tecnologia.

\section{ABSTRACT}

One of the goals of community restaurants should be to ensure adequate meals under sanitary and hygienic criteria. The use of checklists is a resource to assist in the adequacy of good practices in food services. The objective of this work was to evaluate the level of adequacy of good practices through the use of a mobile application in a chain of roast chicken restaurants in southern Brazil. This is a descriptive, quantitative study using secondary data. The results obtained from inspections applied through an instrument used in a mobile cell phone application adapted from Brazilian health legislation were analyzed. In the period investigated, from April 2017 to January 2018, the 143 inspections carried out in the chain's 10 restaurants were evaluated. No relationship was found between the number of inspections and the percentages of sanitary adequacy. The restaurant that had the lowest number of inspections had the highest percentage of non-conformities. The restaurant with the best percentage reached 67\% of adequacy. One establishment reached $76 \%$ of nonconformity. The importance of using technology to support the nutritionist's performance is highlighted.

${ }^{1}$ Professor Adjunto da Universidade Federal do Rio Grande do Sul (UFRGS); Graduação de Nutrição; Departamento de Nutrição; CESAN/HCPA. Doutor em Qualidade Ambiental. E-mail: vjs.nut@terra.com.br

${ }^{2}$ Nutricionista graduada pelo Departamento de Nutrição da Universidade Federal do Rio Grande do Sul. E-mail: karenrigo3@ yahoo.com.br

${ }^{3}$ Professor Adjunto da Universidade Federal do Rio Grande do Sul (UFRGS); Graduação de Nutrição; Departamento de Nutrição; CESAN/HCPA. E-mail: janaina_venzke@hotmail.com 
The use of mobile application features, such as those available for cell phones can be relevant for evaluating results in real-time in restaurants.

Keywords: Food Service, Good Handling Practices, Checklist, Food Safety, Restaurants, Technology.

\section{INTRODUÇÃO}

O acesso à alimentação adequada, tanto em quantidade como em qualidade, está diretamente relacionado com a saúde da população (SERAFIM, 2015). O monitoramento da qualidade dos alimentos deve considerar aspectos sanitários, como o microbiológico e o toxicológico. Nesse contexto, a segurança sanitária busca a proteção da saúde humana, com a preocupação em ofertar o alimento saudável e com garantia de qualidade biológica, sanitária, nutricional e tecnológica à população, considerando as mudanças ocorridas na cadeia de produção até o consumo dos alimentos (BRASIL, 2008).

A produção de refeição para coletividade ocorre em espaços específicos que podem receber nomes como: Unidade de Alimentação e Nutrição (UAN), Unidade Produtora de Refeições (UPR) ou Serviço de Alimentação Coletiva (SAC) (SANTOS; STRASBURG, 2016). Na contextualização do termo, são utilizadas ainda, expressões como: Unidades de Alimentação (UA), serviço de restauração e mercado de foodservice. O termo 'foodservice' é aplicado para designar o fornecimento de refeições fora de casa (RODGERS, 2017).

De acordo com Peccini (2010) a comida pode conferir identidade. O alimento de maneira isolada é algo universal que não transmite identidade de quem o come, como a comida faz. É pensando assim que chamamos os pratos de típicos. Um prato típico representa a cultura de um determinado grupo social. Alimentos como o queijo de Minas, preparações como a feijoada do carioca, o pato no tucupi do Pará, o churrasco do gaúcho, o galeto "al primo canto" da Serra Gaúcha, entre tantos outros, são considerados típicos daquela região (PECCINI, 2010). Restaurantes comerciais, e em especial, os que possuem um apelo cultural, por remeterem a hábitos culturais de alguma etnia, e que por esse motivo, atraem a atenção do público do segmento do turismo, devem manter a preocupação com a segurança dos alimentos oferecidos.

De forma específica, as galeterias são uma modalidade de restaurante. Sua origem remete aos hábitos dos imigrantes italianos da Serra Gaúcha, que tinham por hábito preparar passarinhadas para celebrar grandiosos dias de festa. Porém, no fim da década de 1950, a caça aos passarinhos foi proibida, surgindo o galeto "al primo canto": frango jovem com cerca de 500 gramas e temperado com diversos condimentos. A iguaria era servida acompanhada de pães, polenta, massas e vinho.

O consumo de refeições fora de casa é uma prática que pode apresentar riscos à saúde, como intoxicações alimentares e surtos por doenças transmitidas por alimentos (DTA). Dessa maneira, 
o fornecimento de uma alimentação saudável e segura, deve seguir as legislações higienicossanitárias vigentes deve ser condições inerentes de SAC (ABREU; SPINELLI; PINTO, 2016). Baixos níveis de higiene, durante a preparação dos alimentos, e a ausência de conhecimento sobre a segurança sanitária têm sido apontados como fatores associados às DTA (BEZERRA, 2009).

O risco sanitário deve enfocar a abordagem integral de saúde e considerar o risco nutricional decorrente desse cenário, ampliando a capacidade do Estado, em fazer uso dos instrumentos legais de controle necessários à proteção da saúde da população (BRASIL, 2008). Tais controles devem ser adotados pelos estabelecimentos, produtores de alimentos e de refeições, a fim de garantir a qualidade sanitária e conformidade dos produtos alimentícios, conforme as normas técnicas. Nesse sentido, o uso da tecnologia tem oferecido novos recursos para se alcançar esses objetivos.

O crescimento do mercado de dispositivos móveis tem gerado oportunidades comerciais e sociais em diversas áreas, incluindo a da saúde. Desse modo, desenvolver soluções computacionais, no formato de aplicativos móveis, representa um meio eficaz de disponibilizar a ferramenta e atingir o público-alvo desejado. A utilização de aplicativos móveis na área da saúde está em crescente expansão, pois esse tipo de suporte pode proporcionar aos profissionais alcançarem mais precisão e agilidade em seus trabalhos (BALDO et al., 2015; TIBES; DIAS; ZEM-MASCARENHAS, 2014; CORREIA et al., 2013).

Considerando a crescente procura pelos serviços de alimentação, pela população, e seu importante papel na garantia de fornecimento de alimentos seguros aos consumidores, é importante a avaliação das condições higienicossanitárias dos estabelecimentos institucionais e comerciais, que atendem a população, a fim de evitar a ocorrência de DTA. Nesse sentido, esse estudo tem por objetivo mostrar a avaliação das adequações de boas práticas por meio da utilização de aplicativo móvel, em uma rede de galeterias no sul do Brasil.

\section{METODOLOGIA}

Esse estudo é do tipo descritivo, tem abordagem quantitativa e utiliza dados secundários (PRODANOV; FREITAS, 2013). A empresa pesquisada possui restaurantes na Serra Gaúcha e Região Metropolitana de Porto Alegre (Rio Grande do Sul), sendo, no total, 10 restaurantes, que compuseram a amostra desse estudo. Os dados utilizados foram obtidos com a administração da rede de galeterias.

Foram analisados os resultados obtidos de inspeções aplicadas por meio de instrumento utilizado em aplicativo móvel de celular. O instrumento utilizado foi elaborado e adaptado a partir da Resolução da Diretoria Colegiada (RDC) no 216/2004 da Agência Nacional de Vigilância Sanitária - (ANVISA) e possui 58 itens divididos em seis grupos, conforme apresentado no Quadro 1 (BRASIL, 2004). 
Quadro 1 - Caracterização dos grupos avaliados em inspeção sanitária de restaurantes de galeterias do RS.

\begin{tabular}{|l|c|l|}
\hline \multicolumn{1}{|c|}{ GRUPO } & $\mathbf{N}^{\mathbf{0}}$ DE ITENS & \multicolumn{1}{c|}{ ITENS AVALIADOS } \\
\hline 01 - Estrutura Física & 08 & $\begin{array}{l}\text { Paredes, teto, forro, piso, iluminação, ralos, vestiários, portas e aberturas } \\
\text { regulamentados e em boas condições de higiene. }\end{array}$ \\
\hline $\begin{array}{l}02 \text { - Higienização de } \\
\text { Instalações, equipamentos, } \\
\text { mobiliários e utensílios }\end{array}$ & 14 & $\begin{array}{l}\text { Limpeza e higienização correta de: equipamentos, refrigeradores, utensílios, } \\
\text { caixas de gordura, área de manipulação, pias, panos, esponjas e etc. } \\
\text { Uso de álcool a 70\% e saneantes adequados, bem como seus registros completos. }\end{array}$ \\
\hline 03 - Manipuladores & 05 & $\begin{array}{l}\text { Higiene e apresentação pessoal adequada (uniforme, uso de touca, unhas, } \\
\text { adornos, objetos pessoais). } \\
\text { Higienização adequada das mãos - procedimento e periodicidade. }\end{array}$ \\
\hline 04 - Equipamentos e & 09 & $\begin{array}{l}\text { Temperaturas de equipamentos (refrigeradores, termômetros) adequadas, com } \\
\text { manutenção preventiva, bom estado de conservação e registros completos. } \\
\text { Possuir lixeiras com tampa e pedal. }\end{array}$ \\
\hline 05 - Armazenamento & 13 & $\begin{array}{l}\text { Correta identificação e armazenamento dos alimentos perecíveis e não perecíveis. } \\
\text { Controle de validade, correta refrigeração e congelamento, Primeiro que Vence, } \\
\text { Primeiro que sai (PVPS); contaminação cruzada, organização de estoque, } \\
\text { saneantes e controle de possíveis contaminantes. }\end{array}$ \\
\hline $\begin{array}{l}06 \text { - Preparação do } \\
\text { alimento }\end{array}$ & 09 & $\begin{array}{l}\text { Inspeção, monitoramento, higienização, pesagem, controle de temperaturas } \\
\text { (descongelamento, reaquecimento) e registros adequados. }\end{array}$ \\
\hline
\end{tabular}

Fonte: Construção dos Autores

O aplicativo foi desenvolvido por uma empesa privada, fundada no ano de 2012, com o objetivo de padronizar serviços de segurança alimentar, processos de qualidade, dentre outros. A plataforma do aplicativo pode ser usada em vários ramos de empresas, como indústrias e dos segmentos de alimentação, saúde e entretenimento (CHECKLIST FÁCIL, 2018).

Os dados coletados foram referentes à totalidade das inspeções realizadas, com o aplicativo móvel, em cada um dos restaurantes da rede de galeterias, no período de abril de 2017 a janeiro de 2018.

A análise dos dados, em relação à classificação de conformidade das condições higienicossanitárias de cada restaurante, seguiu o critério de parâmetros preconizados na RDC no 275/2002 da ANVISA em relação ao percentual de atendimento dos itens: a) Grupo 1 - de 0 até 50\%; b) Grupo 2 de 51 a $75 \%$; de 76 a 100\% (BRASIL, 2002).

Os resultados consolidados de todos os restaurantes foram analisados em frequências absolutas e relativas, médias e percentuais calculadas no software Microsoft ${ }^{\circledR}$ Excel 2010@. Esse estudo foi autorizado pela Comissão de Pesquisa da Faculdade de Medicina da Universidade Federal do Rio Grande do Sul sob n ${ }^{0} 35962 / 2018$.

\section{RESULTADOS E DISCUSSÃO}

Os resultados, apresentados na Tabela 1 e no Gráfico 1, mostram as informações consolidadas das 143 inspeções realizadas com o aplicativo móvel, nos 10 restaurantes da rede de galeterias. Desse total, 80\% deles encontram-se alocados em cidades da região da Serra Gaúcha (RS). Essas localizações são bem variadas e perfazem cinco cidades distintas, no estado do Rio Grande do Sul. 
Uma das cidades, situada no nordeste do estado, conta com quatro estabelecimentos, outras contam com apenas um.

Os restaurantes localizados na cidade de Porto Alegre (POA 1 e POA 2) obtiveram uma média de 18,5 inspeções por período/local. Já os da região da Serra (SER 1 a SER 8) 13,25. Identificou-se que o restaurante SER 2 teve menos que uma inspeção por mês, em contrapartida com o POA 2, que chegou a ter mais que duas inspeções mensais.

Tabela 1 - Avaliação das condições higienicossanitária de restaurantes de uma rede de galeterias. RS, abril/2017- janeiro/2018.

\begin{tabular}{|c|c|c|c|c|c|c|c|c|c|}
\hline \multicolumn{10}{|c|}{ Resultados } \\
\hline \multicolumn{2}{|c|}{ Grupo (n ${ }^{0}$ de itens) } & \multirow{2}{*}{$\begin{array}{l}\text { G1 } \\
\text { C }\end{array}$} & \multirow{2}{*}{$\begin{array}{c}\text { G2 } \\
\mathbf{C} \\
\end{array}$} & \multirow{2}{*}{$\begin{array}{c}\text { G3 } \\
\text { C } \\
\end{array}$} & \multirow{2}{*}{$\begin{array}{c}\text { G4 } \\
\text { C }\end{array}$} & \multirow{2}{*}{$\begin{array}{c}\text { G5 } \\
\text { C }\end{array}$} & \multirow{2}{*}{$\begin{array}{c}\text { G6 } \\
\text { C } \\
\end{array}$} & \multicolumn{2}{|c|}{$\begin{array}{l}\text { Total de itens } \\
\text { Avaliados (\%) }\end{array}$} \\
\hline RESTAURANTE & Inspeções & & & & & & & $\mathbf{C}$ & $\mathrm{NC}$ \\
\hline POA 1 & 16 & 37 & 6 & 37 & 63 & 25 & 63 & 39 & 61 \\
\hline POA 2 & 21 & 10 & 52 & 38 & 67 & 38 & 38 & 40 & 60 \\
\hline SER 1 & 14 & 50 & 43 & 50 & 0 & 43 & 43 & 38 & 62 \\
\hline SER 2 & 9 & 0 & 11 & 44 & 22 & 44 & 22 & 24 & 76 \\
\hline SER 3 & 12 & 33 & 33 & 8 & 75 & 67 & 75 & 49 & 51 \\
\hline SER 4 & 16 & 56 & 75 & 50 & 75 & 75 & 69 & 67 & 33 \\
\hline SER 5 & 16 & 75 & 56 & 31 & 0 & 75 & 50 & 48 & 52 \\
\hline SER 6 & 13 & 46 & 23 & 46 & 77 & 77 & 54 & 54 & 46 \\
\hline SER 7 & 14 & 57 & 7 & 7 & 50 & 64 & 36 & 37 & 63 \\
\hline SER 8 & 12 & 17 & 0 & 17 & 58 & 50 & 42 & 31 & 69 \\
\hline \multicolumn{2}{|c|}{ Adequação \% por grupo } & 38,1 & 30,6 & 32,8 & 48,7 & 55,8 & 49,2 & 42,7 & 57,3 \\
\hline
\end{tabular}

Legendas: $\%=$ percentual; $\mathrm{G}=$ grupo; $\mathrm{C}=$ conforme; $\mathrm{NC}=$ não conforme; POA: restaurantes localizados na cidade de Porto Alegre; SER: restaurantes situados na região da Serra Gaúcha; Grupos: G1 - Estrutura Física; G2 - Higienização de Instalações, equipamentos, mobiliários e utensílios; G3 - Manipuladores; G4 - Equipamentos e utensílios; G5 - Armazenamento; G6 - Preparação do alimento. Valores destacados em negrito por opção dos autores.

Gráfico 1 - Avaliação do percentual de inadequação total por grupo em rede de galeterias (RS), abril/2017 - janeiro/2018.

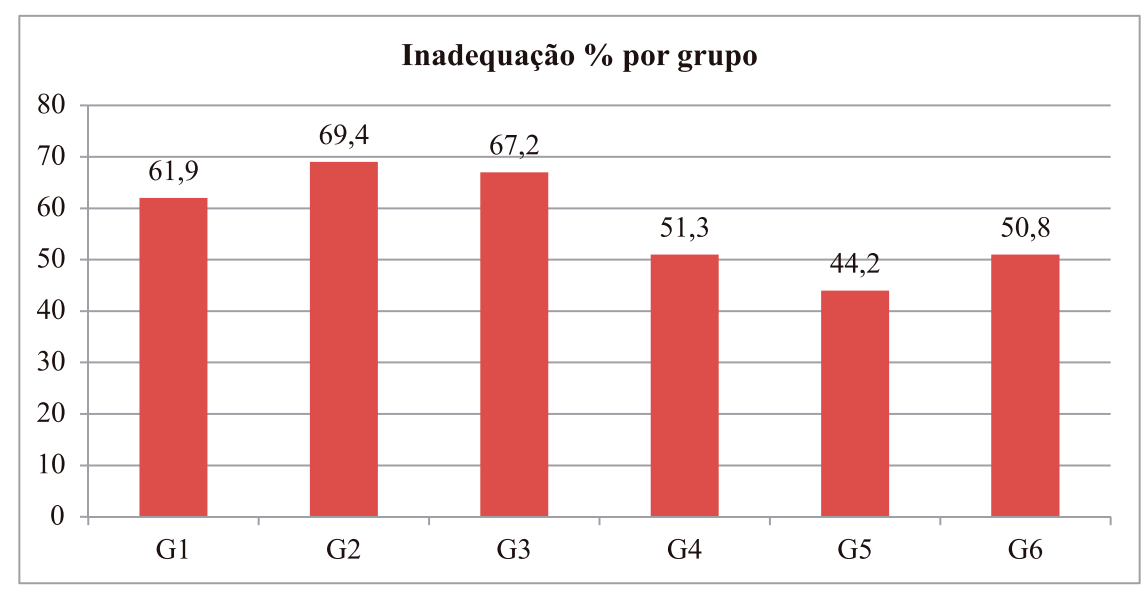

Fonte: Construção dos Autores

Legenda: G1 - Estrutura Física; G2 - Higienização de Instalações, equipamentos, mobiliários e utensílios; G3 - Manipuladores; G4 - Equipamentos e utensílios; G5 - Armazenamento; G6 - Preparação do alimento. 
O grupo G1, que contempla os aspectos relacionados à estrutura e edificação, mostrou situações específicas quanto aos percentuais de adequação. Nenhum dos restaurantes teve avaliação de conformidade superior a 75\%. Destaca-se que um dos locais não teve nenhuma adequação. Na avaliação dos itens desse grupo foi identificado que os problemas mais recorrentes foram relacionados com: organização e limpeza de vestiários, proteção contra roedores em aberturas e teto com forro lavável e impermeável. A legislação federal RDC nº 216 da ANVISA enfatiza o dever dos estabelecimentos em manter edificação e estrutura adequadas, para não prejudicar o fluxo da operação, facilitar a organização e limpeza (BRASIL, 2004).

A proteção contra roedores em aberturas deve existir e ser eficaz, assim como o controle químico. Porém, para Tondo e Bartz (2011) os vetores não podem encontrar alimento exposto e desprotegido em serviços de alimentação, tornando-se estes um atrativo para os roedores. Faz-se necessário a utilização de embalagens, lixeiras com tampa e aberturas protegidas.

O resultado da avaliação desse grupo, foi bem distinto de outros encontrados na literatura. Boff e Strasburg (2018), em um estudo sobre a efetividade de boas práticas em UAN, identificaram 55,5\% de inadequações nos registros relacionados com itens de edificação. Para Fonseca et al. (2010), em um estudo transversal realizado em 2005, 92\% a 100\% dos restaurantes apresentaram inadequação em diversos itens relacionados à edificação, com enfoque em: teto, organização e higienização de ambientes, aberturas e controle integrado de vetores e pragas urbanas. E, no trabalho de De Morais et al. (2016), a adequação para o item de estrutura física atingiu $80 \%$ dos restaurantes pesquisados.

O grupo G2, que relaciona os itens de higienização de instalações, equipamentos, mobiliários e utensílios, mostrou percentuais mais altos de não conformidades, em comparação a outros grupos. Destaca-se que, $50 \%$ dos restaurantes tiveram $25 \%$ ou menos de adequação em relação aos itens avaliados nesse grupo. Os itens que apresentaram maior inadequação foram os relacionados com uso de álcool 70\% para desinfecção de superfícies, limpezas e os respectivos registros adequados desses procedimentos. Segundo a classificação do Center of Diseases Control and Prevention (CDC), o álcool a 70\% é o germicida intermediário mais utilizado para desinfecção de superfícies (GRAZIANO et al., 2013).

Gomez (2012) verificou como a desinfecção incorreta de superfícies pode prejudicar o funcionamento da operação. O material orgânico, presente em qualquer superfície, desde bancadas, tábuas de corte, facas, liquidificadores, entre outros, se não forem desinfetados corretamente podem vir a se tornar um fator de risco para a contaminação de alimentosvisando oferecer alimento seguro. O Campus Monte Castelo do Instituto Federal do Maranhão (IFMA.

Resultado insatisfatório semelhante foi encontrado por Nunes, Aranha e Vulcano (2014), pois, em um primeiro momento, anterior a treinamentos de capacitação com os funcionários de uma UAN hospitalar, a limpeza estava presente em 70\% dos equipamentos e superfícies, já a desinfecção (com uso de álcool a 70\%) não foi verificada em nenhuma prática avaliada. 
Da mesma forma, Tondo e Bartz (2011) citam que, para alguns especialistas e fiscais, o que não está registrado e/ou documentado, não existe. Logo, um estabelecimento sem registros não consegue comprovar seus feitos. Para esses autores ainda, ensinar ao funcionário o operacional e o burocrático é de fundamental importância, pois em caso de surtos ou intoxicações, os registros podem ajudar na defesa e argumentação do estabelecimento (TONDO; BARTZ, 2011).

O estudo de Boff e Strasburg (2018) encontrou 65,3\% de adequação, referente à parte de documentação e registros, de três modalidades diferentes de restaurantes avaliadosem oito grupos, que dizem respeito à comprovação dos procedimentos desenvolvidos em três modalidades de SAC: Institucionais Públicos, Privados de Buffet e/ou a quilo e Lanchonetes. As visitas aos SAC ocorreram entre janeiro e março de 2015 na cidade de Porto Alegre/RS. Os dados obtidos foram organizados e calculadas no software da Microsoft Office Excel ${ }$, sendo classificados conforme a RDC 275/2002. Resultados: Foram visitados e inspecionados 15 estabelecimentos distribuídos igualitariamente em cada modalidade. Foi observado que os restaurantes públicos e privados conseguiram atingir um nível de adequação regular. O percentual de adequação no total dos locais ficou em 60,5\%. Na avaliação por grupos, o manejo de resíduos apresentou adequação de 93,3\% nos locais, enquanto o de edificação e instalações físicas teve o menor percentual (55,5\%. Em estudo conduzido por Bernardo et al. (2014), em hotéis de Belo Horizonte, estes registros ou não estavam preenchidos ou não estavam conforme a legislação exige. Läikko-Roto (2014) identificaram em um estudo que os documentos de controle foram preenchidos e realizados em estabelecimentos, em que havia uma pessoa ou técnico, com experiência, responsável pela fiscalização e capacitação.

O grupo G3, que contempla os itens relacionados aos manipuladores de alimentos, variou bastante e obteve o segundo menor percentual geral de conformidades. Dos seis grupos avaliados, foi nesse que os restaurantes tiveram a pior avaliação geral, pelo fato de nenhum deles ter obtido avaliação de conformidade superior a 50\%. Analisando-se os itens, os problemas mais recorrentes foram com uniformes, uso de touca, cabelos protegidos e higienização adequada de mãos.

O manipulador de alimentos, além de ser considerado um dos principais responsáveis pela contaminação dos alimentos, pode ser um portador assintomático e/ou uma fonte de transmissão de patógenos para os alimentos, por meio das mãos contaminadas (BRASIL, 2016). Outros estudos citam, ainda, outras vias de contaminação, tanto na parte externa do corpo (mãos, pele e cabelo), na parte interna (boca, garganta e nariz) como em secreções (fezes, urina, saliva e suor) (MARCHI et al., 2011; SILVA et al., 2015).

Shinbaum, Crandall e O’bryan (2016), em um estudo realizado nos Estados Unidos, concluíram que $98 \%$ dos surtos alimentares, que ocorreram em restaurantes, se deu por falta de higiene dos funcionários ou por práticas inadequadas na preparação dos alimentos. Resultado semelhante foi encontrado por Mello et al. (2010), em restaurantes públicos populares do Rio de Janeiro, e por 
Guimarães e Figueiredo (2010) em panificadoras no Pará, em que a frequência e higienização das mãos era inadequada, bem como evidenciado o uso de adornos.

Um estudo realizado em Vitória/ES avaliou dois serviços de alimentação e nutrição, o item manipuladores, nas duas unidades, ficou com média de $65 \%$ de adequação. As maiores inadequações foram pela não higienização de mãos e uso de roupas pessoais no horário de trabalho. Ou seja, embora os percentuais distintos, os itens inadequados ficaram semelhantes (SILVA et al., 2015). No estudo de Rigui e Basso (2016) em instituições filantrópicas de longa permanência o aspecto mais grave foi o referente ao uniforme inadequado dos manipuladores.

O grupo G4 contempla os itens relacionados com equipamentos e utensílios. No entanto destaca-se que três restaurantes da Serra Gaúcha tiveram valores iguais ou superiores a $75 \%$ de adequação. Entre os itens, os que apresentaram inadequações mais recorrentes foram relacionados com calibração de termômetro e temperaturas dos refrigerados adequadas e registradas.

Resultado semelhante foi encontrado por Silveira, Granada e Monks (2016), ao avaliar os procedimentos de boas práticas dos restaurantes cadastrados no Projeto-Piloto de Categorização para a Copa do Mundo FIFA, na cidade de Pelotas/RS. Nesse estudo, foi identificado que grande parte dos restaurantes avaliados não possuía sequer termômetro e os que possuíam não estavam calibrados. Logo, os registros e planilhas estavam inadequados.

Uma das ferramentas de controle de crescimento microbiano são as temperaturas. Logo, como garantia de que os alimentos sejam servidos em temperaturas adequadas, os equipamentos que o condicionam devem possuir controle e registro, conforme preconizado pela legislação vigente (SÃO JOSÉ; COELHO; FERREIRA, 2011)objetivou-se avaliar as condições físicas e higiênico-sanitárias em uma unidade de alimentação e nutrição institucional quanto ao atendimento a regulamentos federais sobre boas práticas. Foi realizado estudo transversal em uma Unidade de Alimentação e Nutrição institucional que distribuía 320 refeições por dia. Para avaliação utilizou-se a lista de verifi cação proposta no Anexo II da Resolução RDC 275/2002. O controle de temperatura das preparações e dos equipamentos foi realizado utilizando planilha de controle da própria unidade. A avaliação por blocos evidenciou que o maior percentual de adequação foi verifi cado no bloco manipuladores e o maior percentual de inadequação, no bloco documentação. Quanto à avaliação das preparações, as quentes apresentaram melhor adequação no que se refere a temperaturas analisadas, destacando o resultado obtido para o arroz e o feijão, que atingiram 100\% de adequação. Temperaturas inferiores a $60^{\circ} \mathrm{C}$ foram identifi cadas para guarnição, prato principal e opção. Para as preparações frias, especifi camente saladas, foram detectadas inadequações, considerando o valor inferior a $10^{\circ} \mathrm{C}$ como temperatura aceitável. Entre os equipamentos quentes de distribuição, o balcão foi o que apresentou maior percentual de adequação no turno do almoço e jantar (100\%.

O grupo G5 teve como abrangência os itens relacionados com armazenamento. Na avaliação geral por grupos, esse foi o que teve a melhor média geral de adequação. Semelhante ao G4, 
três restaurantes alcançaram adequação igual ou superior a $75 \%$, sendo que, a melhor pontuação (77\%) foi do mesmo estabelecimento nos dois grupos. Analisando-se os itens, os problemas mais recorrentes foram os relacionados com alimentos com data fora da validade, sem a devida identificação e sem o selo de inspeção sanitária nos produtos de origem animal.

Situação semelhante como: a falta de identificação de data, prazo de validade, falta de rotulagem em embalagens já abertas, carnes cruas armazenadas sem proteção e selo de procedência e/ou produtos pré-preparados armazenados sem identificação, foram encontrados no estudo de Silveira, Granada e Monks (2016).

O grupo G6, contemplou os itens de preparação do alimento. Em nenhum restaurante os percentuais de conformidades foram superiores a 75\%. Entre os itens, os que apresentaram mais recorrentes inadequações foram: higienização correta (diluição e tempo) de saladas e inspeção e pesagem no recebimento de mercadorias. Resultado semelhante foi encontrado por Rigui e Basso (2016) que identificaram a falha de higienização de hortifrutigranjeiros, devido a inadequações no processo relativo à falta de informação sobre a quantidade de cloro e volume de água utilizados. Resultados encontrados por Moreira e Deus (2017), na categorização do risco sanitário em lanchonetes, mostraram ausência do uso de produtos para a higienização dos alimentos na maioria dos estabelecimentos.

Levando em consideração que o Brasil possui condição favorável à ocorrência de doenças parasitárias, pelo clima e situação socioeconômica, as hortaliças podem se tornar um agravo para estas doenças. Quando consumidas cruas (saladas) e não higienizadas corretamente (tempo x diluição) podem conter microrganismos resistentes à ação do cloro (GONÇALVES; SILVA; STOBBE, 2013).

Em relação ao recebimento de matérias-primas, estudos mostram baixo percentual de adequação, sendo que a maioria se dá por falta de inspeção no recebimento das mercadorias, organização, identificação e ausência de registros para monitoramento do peso e da temperatura. Ainda, ficou comprovado que a maior incidência é relacionada à verificação da temperatura no recebimento e armazenamento das matérias-primas perecíveis (SILVA et al., 2015; OLIVEIRA et al., 2017).

O percentual geral, de adequações e não adequações, foi analisado agrupando todos os grupos e itens para cada um dos restaurantes. Dessa forma, o restaurante que obteve o maior percentual de adequação atingiu 67\%. Em relação a não conformidade, um estabelecimento atingiu 76\%. Na avaliação seguindo os protocolos da RDC $n^{\circ}$ 275/2002 da ANVISA, dois estabelecimentos seriam classificados como no grupo 2 , e os demais (80\%) no grupo 1 - ou seja, com menos de $50 \%$ de adequação geral.

Não foram encontradas relações entre a quantidade de inspeções com os percentuais de adequação higienicossanitárias. O restaurante que teve o menor número de inspeções apresentou o maior percentual de inconformidades. No entanto, o restaurante que teve o maior número de inspeções, não apresentou o melhor desempenho geral, em relação ao número de conformidades. Tanto os dois restaurantes com melhor avaliação geral quanto os dois com pior desempenho estão situados na Serra Gaúcha. 
Ainda, os restaurantes situados na região da Serra Gaúcha, próximos um do outro, não mantiveram número de inspeções e percentuais de conformidades semelhantes. Já os situados na grande Porto Alegre, foram semelhantes nos percentuais de conformidades, porém discrepantes no número de inspeções. Para o controle e realização de boas práticas de higiene e manipulação é de grande importância à presença do responsável técnico habilitado, bem como fazer uso de treinamentos e capacitações (SILVA et al., 2015).

Realizar avaliações e monitoramento de condições higienicossanitárias é fundamental para qualquer tipo de serviço que ofereça alimentação para coletividade. Dessa forma, adaptações das legislações oficiais podem e devem ser utilizadas, como no caso de instrumento desenvolvido para avaliar as condições de copas hospitalares (VARGAS et al., 2018); em instituições filantrópicas de longa permanência (RIGUI; BASSO, 2016) ou em unidades produtoras de refeições.

Além disso, deve ser evidenciada a utilização do recurso para realizar as inspeções de caráter higienicossanitário. Isso porque os aplicativos móveis, no âmbito da nutrição, têm sido utilizados especialmente em situações de consumo alimentar e avaliação de estado nutricional (BALDO et al., 2015; CORREIA et al., 2013).

Como limitações, destacamos no presente estudo situações que podem ser inerentes à utilização de dados secundários. Como exemplo, ressaltamos em especial a percepção da avaliação dos itens por parte de quem fez a aplicação do instrumento do aplicativo móvel nos restaurantes.

\section{CONCLUSÕES}

O acompanhamento rotineiro das condições higienicossanitárias das instalações e de processos, destaca-se como uma atribuição do nutricionista, em estabelecimentos que forneçam refeições para a coletividade. Os nutricionistas devem zelar pela manutenção da qualidade e segurança dos alimentos, fazer uso de seu conhecimento técnico para orientar e capacitar outros colaboradores que compõem a equipe do estabelecimento.

Este trabalho avaliou a adequação das condições higienicossanitárias em restaurantes de uma rede de galeterias, por meio da utilização de um instrumento de inspeção de aplicativo móvel. Foi possível identificar, a partir dos resultados, a existência de diferenças importantes entre os dez restaurantes.

Deve ser destacada a importância de se fazer uso da tecnologia, para dar suporte na atuação do nutricionista. Poder utilizar recursos de aplicativos móveis, como os disponíveis para aparelhos celulares, podem ser relevantes para fazer a avaliação em tempo real dos resultados. Para fins comparativos, ainda, podem ser verificados outros aspectos como: dimensão física e estrutural de cada restaurante, capacidade e número de refeições servidas, tempo de atividade de cada restaurante e quantidade de funcionários, entre outros. 
Dessa maneira, avalia-se como relevante a realização de estudos que identifiquem, além das condições higienicossanitárias, a frequência com que uma mesma inconformidade pode se propagar em diferentes estabelecimentos. E, a partir dessas informações, fazer uso de medidas e desenvolver planos de ação e de melhorias para evitar risco de doenças transmitidas por alimentos, para garantir a segurança alimentar e nutricional dos comensais.

\section{REFERÊNCIAS}

ABREU, E. S; SPINELLI, M. G. N; PINTO, A. M. DE S. Gestão de unidades de alimentação e nutrição: um modo de fazer. 6. ed. São Paulo: Metha, 2016. 400 p.

BALDO, C; ZANCHIM, M. C; KIRSTEN, V. R; MARCHI, A. C. B. Diabetes Food Control - Um aplicativo móvel para avaliação do consumo alimentar de pacientes diabéticos. Rev Eletron de Comun Inf Inov Saúde, v. 9, n. 3, p. 1-12, 2015. Disponível em: https://bit.ly/3fjhfac. Acesso em 20 out. 2019.

BERNARDO, P. V; VALENTIM, E. C. N; OLIVEIRA, A. E. S; RAMOS, S. A. Avaliação das Boas Práticas na Produção de Refeições na Rede Hoteleira de Belo Horizonte. UNOPAR Cient Ciênc Biol Saúde, v. 16, n. 4, p. 265-270, 2014.

BEZERRA, I. N. Alimentação fora do domicílio no Brasil e sua associação com obesidade : pesquisa de orçamentos familiares 2002-2003. 2009. 126 f. Dissertação (Mestrado em Saúde Coletiva) Universidade do Estado do Rio de Janeiro. Rio de Janeiro, 2009.

BOFF, J. M; STRASBURG, V. J. Avaliação da Efetividade de Boas Práticas em Serviços de Alimentação Coletiva em uma Capital Brasileira. Saúde (Santa Maria), v. 44, n. 1, 2018. Disponível em: https://bit.ly/39PCPC9. Acesso em: 14 abr. 2019.

BRASIL. Agência Nacional de Vigilância Sanitária. Resolução RDC n 275, de 21 de outubro de 2002. Dispõe sobre o Regulamento Técnico de procedimentos operacionais padronizados aplicados aos estabelecimentos produtores/industrializadores de alimentos e a lista de verificação das boas práticas de fabricação. Diário Oficial [da] República Federativa do Brasil, Brasília, DF, 8 jan. 2002.

BRASIL. Agência Nacional de Vigilância Sanitária. Resolução RDC n 216, de 15 de setembro de 2004. Estabelece procedimentos de Boas Práticas para serviços de alimentação a fim de garantir as condições higiênico-sanitárias do alimento preparado. Diário Oficial [da] República Federativa do Brasil, Brasília, DF, 16 set. 2004. 
BRASIL. Política nacional de alimentação e nutrição. Ministério da Saúde. Secretaria de Atenção à Saúde. Departamento de Atenção Básica. 2. ed. Brasília: Ministério da Saúde, 2008.

BRASIL. Vigilância epidemiológica das doenças transmitidas por alimentos. Ministério da Saúde. Secretaria de Vigilância em Saúde, 2016. Disponível em: https://bit.ly/31eJfql. Acesso em: 20 mar. 2019.

CHECKLIST FÁCIL. [website]. Ferramenta eletrônica de padronização de serviços. Porto Alegre, 2018. Disponível em: https://www.checklistfacil.com. Acesso em 09 fev. 2018.

CORREIA, R. D; CHIARI, N. S; ALVES, D; NAVARRO, A. M; NutriMobile: Um sistema de avaliação do estado nutricional de pacientes hospitalizados para dispositivos móveis. Revista Brasileira de Inovação Tecnológica em Saúde, v. 3, n. 3, p. 1-10, 2013.

DE MORAIS, N.A.R.; FERNANDES, R.C.S.; ALMEIDA LIMA, M,; DE ABREU, E.S.; CHAUD, D.M.A. Avaliação das condições higienicossanitárias de unidades produtoras de refeição na região central de São Paulo. Disciplinarum Scientia. Série: Ciências da Saúde, Santa Maria, v. 17, n. 2, p. 249-256, 2016.

FONSECA, M. P.; MANFRIDINI, L. A.; SÃO JOSÉ, J. F. B.; TOMAZINI, A. P. B.; MARTINI, H. S. D.; RIBEIRO, R. C. L.; SANT'ANA, H. M. P. Evaluation of physical and functional conditions of commercial restaurants to implementation of good practices. Alim. Nutr., Araraquara, v. 21, n. 2, p. 251-257, abr./jun. 2010 .

GOMEZ, G. M. C. B. M. Adequação às normas de higiene operacional em unidade de alimentação e nutrição (UAN). 2012. 102 f. Dissertação (Mestrado em Ciência e Tecnologia de Alimentos) Universidade Federal Rural do Rio de Janeiro, 2012.

GONÇALVES, R. M; SILVA, S. R. P; STOBBE, N. S. Frequência de Parasitos em Alfaces (Lactuca Sativa) consumidas em Restaurantes Self-Service de Porto Alegre, Rio Grande Do Sul, Brasil. Revista de Patologia Tropical, v. 42, n. 3, p. 323-330, 2013. Disponível em: https://bit.ly/2PijM9U. Acesso em: 04 set 2019.

GRAZIANO M. U; GRAZIANO K. U, PINTO F. M. G, BRUNA C. Q. M, Queiroz R. Q. Lascala C. A. Eficácia da desinfecção com álcool $70 \%(\mathrm{p} / \mathrm{v})$ de superfícies contaminadas sem limpeza prévia. Rev. Latino-Am. Enfermagem, v. 21, n. 2, 2013. 
GUIMARÃES, S. L; FIGUEIREDO, E. L. Avaliação Das Condições Higiênico-Sanitárias De Panificadoras Localizadas No Município De Santa Maria Do Pará-Pa. Revista Brasileira de Tecnologia Agroindustrial, v. 4, n. 2, p. 198-206, 2010. Disponível em: https://bit.ly/39R6LO3. Acesso em: 18 abr. 2019.

LÄIKKÖ-ROTO, M. N. T. Restaurant business operators' knowledge of food hygiene and their attitudes toward official food control affect the hygiene in their restaurants. Food Control, [s. 1.], v. 43, n. 2003, p. 1-240, 2014. Disponível em: https://bit.ly/2XndoCM. Acesso em: 17 nov 2019.

MARCHI, D. M; BAGGIO, N; TEO, C. R. P. A; BUSATO, M. A. Ocorrência de surtos de doenças transmitidas por alimentos no Município de Chapecó, Estado de Santa Catarina, Brasil, no período de 1995 a 2007. Epidemiologia e Serviços de Saúde, [s. 1.], v. 20, n. 3, p. 401-407, 2011. Disponível em: https://bit.ly/2BYCrEY. Acesso em: 04 set. 2019.

MELLO, A, G; GAMA, M. P; MARIN, V. A; COLARES, L. G. T. Conhecimento dos manipuladores de alimentos sobre boas práticas nos restaurantes públicos populares do Estado do Rio de Janeiro. Brazilian Journal of Food Technology, [s. 1.], v. 13, n. 1, p. 60-68, 2010. Disponível em: https://bit.ly/ 3k8qkGj. Acesso em: 07 dez 2019.

MOREIRA, L. R. R.; DEUS, G. I. Avaliação e categorização do risco sanitário de lanchonetes universitárias antes e após orientações técnicas. Higiene Alimentar, v. 31, n. 817, p. 31-36, 2017.

NUNES, C. N. M.; ARANHA, F. Q.; VULCANO, D. S. B. Implantação dos Procedimentos Operacionais Padronizados (POPs) de Higienização e Desinfecção dos equipamentos e utensílios em uma Unidade de Alimentação e Nutrição Hospitalar. Rev. Simbio-Logias, v. 7, n. 10, p. 34-48, 2014.

OLIVEIRA, C. C; BRASIL, C. C. B; SILVA, J. P; PEREIRA, L. S; VERDUM, D. P; ROIG, E. C. C; BOHRER, C. T; BOTTARO, S. M. Boas práticas de manipulação em estabelecimentos produtores de alimentos de uma cidade da região noroeste do Rio Grande do Sul. Segurança Alimentar e Nutricional, Campinas, v. 24, n. 55, p. 141-152, 2017.

PECCINI, R. História e Cultura da Alimentação : A Galeteria Peccini e o Patrimônio de Caxias do Sul. 2010. 154 f. Dissertação (Mestrado em Turismo) - Universidade de Caxias do Sul, Caxias do Sul, 2010. 
PRODANOV, C. C; FREITAS, E. C. Metodologia do trabalho científico: métodos e técnicas da pesquisa e do trabalho acadêmico.Novo Hamburgo: Feevale, 2013. Disponível em: https://bit.ly/33ynxkf. Acesso em: 21 ago. 2019.

RIGUI, K.S.; BASSO, C. Boas práticas de manipulação de alimentos em instituições filantrópicas de longa permanência de idosos. Disciplinarum Scientia. Série: Ciências da Saúde, Santa Maria, v. 17, n. 2, p. 279-290, 2016.

RODGERS, S. International Journal of Hospitality Management Food service research : An integrated approach. International Journal of Hospitality Management, v. 30, n. 2, p. 477-483, 2017. Disponível em: http://dx.doi.org/10.1016/j.ijhm.2010.05.002. Acesso em: 18 maio. 2018.

SANTOS, A. V; STRASBURG, V. J. Caracterização e análise dos resíduos de embalagens gerados na produção de refeições de um Hospital público de Porto Alegre, RS. Estudo \& Debate, Lajeado, v. 23, p. 296-310, 2016.

SÃO JOSÉ, J. F. B.; COELHO, A. M. I; FERREIRA, K. R. Avaliação das boas práticas em unidade de alimentação e nutrição no município de Contagem-MG. Alim. Nutr., Araraquara, v. 22, n. 3, p. 479-487, 2011. Disponível em: https://bit.ly/33kvysI. Acesso em: 07 jul. 2019.

SERAFIM, A. L. Implementação de Boas Práticas em Serviços de Alimentação na Área de Alimentos e Bebidas de Hotéis. 2015. 141 f. Tese (Doutorado em Ciência e Tecnologia de Alimentos) - Universidade Federal de Santa Maria, Santa Maria, 2015.

SHINBAUM, Samantha; CRANDALL, Philip G.; O’BRYAN, Corliss A. Evaluating your obligations for employee training according to the Food Safety Modernization Act. Food Control, v. 60, p. 12-17, 2016. Disponível em: https://bit.ly/3fqSzg1. Acesso em: 24 out 2019.

SILVA, L. C; SANTOS, D. B; JOSÉ, J. F. B. S; SILVA, E. M. M. Boas Práticas Na Manipulação De Alimentos Em Unidades De Alimentação E Nutrição. DEMETRA: Alimentação, Nutrição \& Saúde, v. 10, n. 4, p. 797-820, 2015. Disponível em: https://bit.ly/39PmnBX. Acesso em: 06 set. 2019.

SILVEIRA, D, M; GRANADA, G. G; MONKS, M. S. Classificação dos Restaurantes de Pelotas-RS, cadastrados no Projeto-Piloto de Categorização de Serviços de Alimentação da Anvisa. Higiene Alimentar, v. 30, p. 43-49, 2016. 
TIBES, C. M. S; DIAS, J. D; ZEM-MASCARENHAS, S. H. Aplicativos móveis desenvolvidos para a área da saúde no brasil: revisão integrativa da literatura. Rev Min Enferm, v. 18, n. 2, p. 471-478, 2014.

TONDO, E. C; BARTZ, S. Microbiologia e Sistemas de Gestão da Segurança de Alimentos. Porto Alegre: Sulina. 263 p.

VARGAS, F.S.; DOS SANTOS, L.P.; DOS SANTOS, V.R.; STRASBURG, V.J. Avaliação da adequação às boas práticas em serviço de nutrição de um hospital universitário de Porto Alegre/RS. Disciplinarum Scientia. Série: Ciências da Saúde, Santa Maria, v 550 . 19, n. 3, p. 549-557, 2018. 
